\title{
The use of mid-infrared spectrometry to predict body energy status of Holstein cows ${ }^{1}$
}

\author{
S. McParland, ${ }^{\star 2}$ G. Banos, $†$ E. Wall, $\ddagger$ M. P. Coffey, $\ddagger$ H. Soyeurt,§\# R. F. Veerkamp,Il and D. P. Berry ${ }^{\star}$ \\ ${ }^{*}$ Animal and Bioscience Research Department, Animal and Grassland Research and Innovation Centre, Teagasc, Moorepark, Co. Cork, Ireland \\ †Department of Animal Production, Faculty of Veterinary Medicine, Aristotle University of Thessaloniki, Greece 52124 \\ ¥Sustainable Livestock Systems Group, Scottish Agricultural College, EH25 9RG United Kingdom \\ $\S$ Gembloux Agro Bio-Tech - University of Liège, Animal Science Unit, Gembloux B-5030, Belgium \\ \#National Fund for Scientific Research, Brussels, Belgium \\ IAnimal Breeding and Genomics Centre, Wageningen UR Livestock Research, Lelystad6708WC, the Netherlands
}

\begin{abstract}
Energy balance, especially in early lactation, is known to be associated with subsequent health and fertility in dairy cows. However, its inclusion in routine management decisions or breeding programs is hindered by the lack of quick, easy, and inexpensive measures of energy balance. The objective of this study was to evaluate the potential of mid-infrared (MIR) analysis of milk, routinely available from all milk samples taken as part of large-scale milk recording and milk payment operations, to predict body energy status and related traits in lactating dairy cows. The body energy status traits investigated included energy balance and body energy content. The related traits of body condition score and energy intake were also considered. Measurements on these traits along with milk MIR spectral data were available on 17 different test days from 268 cows (418 lactations) and were used to develop the prediction equations using partial least squares regression. Predictions were externally validated on different independent subsets of the data and the results averaged. The average accuracy of predicting body energy status from MIR spectral data was as high as $75 \%$ when energy balance was measured across lactation. These predictions of body energy status were considerably more accurate than predictions obtained from the sometimes proposed fat-to-protein ratio in milk. It is not known whether the prediction generated from MIR data are a better reflection of the true (unknown) energy status than the actual energy status measures used in this study. However, results indicate that the approach described may
\end{abstract}

\footnotetext{
Received October 27, 2010.

Accepted March 22, 2011.

${ }^{1}$ The content of this paper is the sole responsibility of the authors, and it does not necessarily represent the views of the European Commission or its services.

${ }^{2}$ Corresponding author: sinead.mcparland@teagasc.ie
}

be a viable method of predicting individual cow energy status for a large scale of application.

Key words: mid-infrared, energy balance, intake, prediction

\section{INTRODUCTION}

Several studies have implicated the extent and duration of negative energy balance as a precursor for impaired health and fertility in dairy cows (Beam and Butler, 1999; Collard et al., 2000; Veerkamp et al., 2000). As such, energy balance would be useful in a breeding program, as it is also known to exhibit significant genetic variation (Veerkamp et al., 2000; Berry et al., 2007). Although some of the importance of energy balance may be captured in a breeding goal that directly includes health and fertility traits, energy balance itself is a measure of the ability of an animal to maintain homeostasis and, therefore, the overall health and welfare status of the animal. However, the limiting factor hindering the inclusion of energy balance in breeding programs worldwide is the high cost associated with its measurement, most accurately measured through the use of expensive, low-throughput calorimeter chambers.

Several alternative methods have been proposed to estimate energy balance in dairy cattle, most considering the differential between energy intake and energy output as milk, maintenance, pregnancy, activity, and growth (Banos and Coffey, 2010). However, such methods also have high associated costs due predominantly to the accurate measurement of cow energy intake. Recently, less expensive alternatives to evaluating energy balance on a large scale have also been presented (Coffey et al., 2003; Friggens et al., 2007; Banos and Coffey, 2010). These methods consider the change in body reserves as a feasible method to evaluate energy balance on potentially large numbers of animals. The drawback to these methods is that they require regular measurements of BCS and BW, neither of which is routinely available on all commercial dairy farms. 
Mid-infrared (MIR) spectral data is routinely used by milk recording organizations worldwide to predict the milk fat and protein composition in milk samples. In addition, it has been shown that some individual milk fatty acids can be accurately predicted using MIR spectroscopy (Soyeurt et al., 2011). Previous studies have attempted to predict energy balance using milk composition measures such as fat-to-protein ratio (Grieve et al. 1986; Heuer et al., 2000; Friggens et al., 2007). Others have shown associations between milk fatty acid composition and energy balance (Stoop et al., 2009). Because these predictor variables of energy balance are themselves predicted using MIR spectroscopy, this suggests that MIR spectral data may be useful as a direct predictor of energy balance.

The objective of this study was to predict body energy status directly from the MIR spectrum of milk. The MIR spectra data routinely generated for the milk samples of all milk-recorded commercial cows could potentially be available in the near future. The approach developed in this study, if successful, will provide a method to obtain estimates of body energy status on large populations of cows at no additional cost to milk recording.

\section{MATERIALS AND METHODS}

\section{Production Data}

Performance data on all lactations from 1,145 cows collected between 1990 and 2010 from the Langhill herd of dairy cows currently stationed at Crichton Royal Farm (Dumfries, Scotland) were available to calculate body energy status. The Langhill experimental herd comprised 2 lines of Holstein cows divergently selected for over $30 \mathrm{yr}$, one line selected for maximum milk fat plus protein kilograms and the other maintained at the national average for milk fat plus protein (Pryce et al., 1999). Cows were further divided into low- and highconcentrate dietary treatments (Pryce et al., 1999). Prior to 2002, milking was undertaken twice daily (0400 and 1600 h). From 2002 onwards, milking was undertaken 3 times daily 0415 (a.m.), 1245 (MD), and 1945 h (p.m.)]; milk yield was recorded for each milking and summed to obtain daily yield. Milk composition was recorded weekly and fat and protein content computed as the weighted average of all samples of an animal on a given day. Dry matter intake was recorded during lactation for 3 successive days, followed by $3 \mathrm{~d}$ of no measurement. Body weight was recorded using automatic weigh scales 3 times per day at milking and averaged to a weekly BW value. Body condition score was assessed by the same operator on a weekly basis using a scale of 0 to 5 with 0.25 intervals, where 0 is emaciated and 5 is obese (Lowman et al., 1976).

Age at calving was defined within parity, as a class variable $(\mathrm{n}=3)$, with animals classed either as (1) less than, (2) greater than, or (3) within 1 standard deviation from the median age at calving. Two seasons of calving were defined: February to August, inclusive, and September to January, inclusive. All performance records from d 5 to 305 for animals in parities 1 through 4 were retained for analysis. Data on 815,129 test days from 3,151 lactations of 1,145 cows were available to compute body energy status.

\section{Computation of Body Energy Status}

Computation of body energy status in the present study was based on the approach and methodology described in detail by Banos and Coffey (2010). Random regression models were fitted in ASReml (Gilmour et al., 2006) to daily milk yield, fat percent, protein percent, DMI, BCS, and BW, to provide daily solutions enabling the calculation of complete lactation profiles for energy balance to be derived. All random regression models were fitted within parity and included the fixed effects of genetic line, feeding group, year of calving by season of calving, age at calving, year of record by month of record, a fourth-order orthogonal polynomial on days postcalving, and the random effect of the interaction of cow by a fourth-order orthogonal polynomial on days postcalving. Six measurement error classes were fitted for DIM $(4<$ DIM $\leq 10,10<$ $\mathrm{DIM} \leq 50,50<\mathrm{DIM} \leq 150,150<\mathrm{DIM} \leq 200,200$ $<\mathrm{DIM} \leq 250$, and $250<\mathrm{DIM})$. Relationships among cows were not accounted for and, thus, the random effects solutions include both the additive and permanent environmental effects of each cow. Daily solutions from each random regression model were visually compared with the actual data collected for each trait and 22 cow lactations were discarded from the analysis because of poor concordance between the actual recorded data and the predicted values from the random regression models on those days.

Two separate measures of body energy status were computed for each day postcalving using the energy system outlined by Emmans (1994). The measures considered were (1) energy balance (Direct_EB; MJ/d), a function of milk yield, fat and protein content, DMI, BW, and BCS; and (2) body energy content (EC; MJ), a function of BW and BCS, predicting body lipid and protein weight. These measures have previously been described in detail (Banos and Coffey, 2010). Additional to Direct_EB and EC, the effective energy intake 
(EEI) per day (MJ/d; Banos and Coffey, 2010) was also computed.

\section{Mid-Infrared Spectrum Data}

Between September 2008 and May 2010, monthly milk samples from the a.m., MD, and p.m. milking on a given day for all Langhill cows $(\mathrm{n}=277)$ were sent to Teagasc Moorepark in Ireland for analysis using an MIR spectrometer (MilkoScan FT6000; Foss, Hillerød, Denmark). The Foss MIR spectrum contains 1,060 data points, which represent the absorption of infrared light through the milk sample at wavelengths in the $900 \mathrm{~cm}^{-1}$ to $5,000 \mathrm{~cm}^{-1}$ region. The MIR spectrum was available for 6,665 milk samples from 18 test dates of 465 lactations from 277 cows. The average number of spectrum records per cow lactation was 5.5 and ranged from 1 to 10 records.

Only spectral data with an actual phenotypic record for all traits of milk yield, fat percent, protein percent, DMI, BW, and BCS available within $7 \mathrm{~d}$ of the corresponding milk sampling date were retained. These edits were undertaken to avoid any potential errors arising from extrapolation or interpolation between sampling with the random regressions. Following edits, a total of 1,883 a.m., 1,731 MD and 1,855 p.m. spectral records were available.

\section{Treatment of Spectral Data}

Spectral data were transformed from transmittance to linear absorbance through a $\log _{10}$ transformation of the reciprocal of the wavelength values (Soyeurt et al., 2011). Boxcar smoothing (i.e., rolling average) was performed on the absorbance spectral data by averaging the spectral data over spectral segments of 5 data points in length, [i.e., each absorbance value was replaced by the average of the absorbance value of its 4 closest neighboring points (Williams, 2007)].

Furthermore, the first derivative was calculated on both the smoothed and unsmoothed absorbance spectral data to bring all spectra to a common baseline and to sharpen absorbance bands. The first derivative (f'x) was calculated as the difference between the spectral value at data point $X$ and the spectral value at data point $\mathrm{X}+5$, where $1 \leq \mathrm{X} \leq 1,055$.

\section{Calibration and Validation Data Sets}

Cows were stratified according to selection line, feeding treatment, and season of calving, and the data split randomly within stratum into 4 equally sized data sets. These were the 4 external validation data sets. For each external validation data set generated, a calibration data set was generated using the remaining $75 \%$ of the data. The calibration data sets were used to develop the prediction equations using splitsample cross-validation. This process was repeated 4 times using a different data set for external validation each time, with the remaining 3 data sets used for the development of the equations, until all data had been tested using external validation exactly once. No cow was ever present in both the calibration and validation data sets for any of the 4 analyses.

To investigate if prediction equations calibrated using only information on cows on one feeding treatment could accurately predict the body energy status of cows on the other feeding treatment, a second set of calibration and validation data sets were created. In these data sets, only cows on the high-concentrate diet were included in the calibration data set, and only cows on the low-concentrate diet were included in the validation data set. The opposite was also tested, where only cows on the low-concentrate diet were included in the calibration data set, with the prediction equation validated on cows on the high-concentrate diet only.

In a similar way, prediction equations were developed to test the predictive ability of equations calibrated on the select line of cows when validated on the control line of cows and vice versa.

\section{Development of Prediction Equations}

Partial least squares regression (Proc PLS; SAS Institute Inc., Cary, NC) was used to predict Direct_EB, EC, BCS, and EEI from the MIR linear absorbance data. Separate predictions were undertaken using both unsmoothed and smoothed spectral data as well as the first derivative. For the purposes of this study, accuracy $(\mathbf{R})$ of prediction was defined as the square root of the coefficient of determination from the regression model of true on predicted values of body energy status. Partial least squares regression analysis uses a data reduction approach, with a variable number of explanatory factors used to explain the maximum amount of variation of the 1,060 correlated wavelength values. As the maximum number of explanatory factors permitted in the prediction models is increased, the $\mathrm{R}$ of the cross-validation tends to improve at the expense of the $\mathrm{R}$ in the external validation. The maximum number of explanatory factors to describe MIR spectra was determined by visually inspecting the changes in $\mathrm{R}$ of split-sample cross-validation and external validation (i.e., validation on data independent of the calibration set) associated with increasing the number of permitted explanatory factors in the model. In a separate series of analyses, when the range of wavelengths to be included 
Table 1. Number of records and mean performance (SD in parentheses) across parities

\begin{tabular}{lccrc}
\hline & \multicolumn{4}{c}{ Parity } \\
\cline { 2 - 5 } Variable & 1 & 2 & 3 & 4 \\
\hline Cows (n) & 164 & 130 & 89 & 35 \\
Records (n) & 835 & 735 & 434 & 141 \\
Milk (kg) & $27.3(6.5)$ & $33.1(8.2)$ & $35.8(9.6)$ & $36.4(9.5)$ \\
Fat (\%) & $3.7(0.5)$ & $3.7(0.6)$ & $3.9(0.6)$ & $3.9(0.5)$ \\
Protein (\%) & $3.2(0.3)$ & $3.2(0.3)$ & $3.2(0.3)$ & $3.2(0.3)$ \\
DMI (kg) & $15.0(3.7)$ & $17.6(4.1)$ & $19.5(3.9)$ & $18.5(4.1)$ \\
BCS & $2.1(0.3)$ & $2.2(0.3)$ & $2.1(0.3)$ & $2.0(0.4)$ \\
BW (kg) & $532.2(58.0)$ & $610.5(64.4)$ & $656.8(56.3)$ & $671.6(60.8)$ \\
Direct_EB ${ }^{1}$ (MJ/d) & $-2.9(25.6)$ & $-5.9(32.5)$ & $-2.9(32.6)$ & $-18.0(38.5)$ \\
Energy content (MJ) & $4,670(780)$ & $5,409(956)$ & $5,749(969)$ & $5,749(1,118)$ \\
Effective energy intake (MJ) & $151.9(37.4)$ & $178.5(41.6)$ & $198.1(40.3)$ & $187.6(41.7)$ \\
Fat-to-protein ratio & $1.17(0.12)$ & $1.15(0.13)$ & $1.21(0.13)$ & $1.21(0.10)$ \\
\hline 1Direct & & &
\end{tabular}

${ }^{1}$ Direct energy balance.

in the model was decided on, milk yield was added to the model as a predictor.

The $\mathrm{R}$ of predicting body energy status measures during early (DIM $<61)$, mid $(60<$ DIM $<180)$, and late (DIM $\geq 180$ ) lactation was also tested using partial least squares regression on MIR spectra and milk yield. Only data from the period of lactation under investigation were included in the development and validation of the prediction equations. All prediction equations were undertaken using a.m., MD, and p.m. samples, separately, and $\mathrm{R}$ of all equations was tested using both split-sample cross-validation and external validation on the 4 calibration and validation data sets, respectively.

To test if the prediction equations generated by this study were more accurate than the previously proposed method of using the ratio of milk fat-to-protein contents (FPR) as a predictor of energy balance (Heuer et al., 2000; Friggens et al., 2007), correlations between FPR and body energy status measures were tested across the entire lactation and for the 3 stages of lactation using p.m. milk samples.

\section{RESULTS}

\section{Data}

Mean performance of all cows included in the analysis for Direct_EB, EC, and EEI, together with their component variables (milk yield, fat percent, protein percent, DMI, BCS, and $\mathrm{BW}$ ), are summarized in Table 1. Performance in the calibration and validation data sets was comparable across all combinations of validation and calibration data sets used. Average Direct_EB was negative for all 4 parities between 5 and 305 DIM, albeit with large associated standard deviations. Although, on average, cows on both feed systems initiated lactation at the same negative energy balance, the low-concentrate group remained in negative energy balance until very late lactation (d 288; Figure 1). In contrast, cows on the high-concentrate diet reached positive energy balance much earlier postcalving. The average range, within cow lactation, for the body energy status traits of Direct_EB, EC, BCS, and EEI was $49 \mathrm{MJ}, 831 \mathrm{MJ}, 0.3$ units, and $50 \mathrm{MJ}$, respectively, across all animals.

Product moment correlations of energy status component variables and FPR with Direct_EB, EC, BCS, and EEI are presented in Table 2 both for the entire lactation and for early lactation. Dry matter intake was the component variable most strongly correlated with Direct_EB both across lactation and in early lactation (DIM <61; correlation of 0.56). Correlations between FPR and all energy status measures were close to zero when measured across lactation or in mid or late lactation (results not shown), however were stronger in early lactation (correlation of -0.28 with Direct_EB). Correlations between milk composition and Direct_EB were weaker in mid and late lactation (results not shown) than correlations in early lactation.

\section{Accuracy of Prediction Across Lactation}

The $\mathrm{R}$ of predicting the studied traits was dependent on the number of explanatory factors permitted in the prediction equations (Figure 2). As expected, the $\mathrm{R}$ of predicting Direct_EB, EC, BCS, and EEI was always lower in the external validation data set compared with the $\mathrm{R}$ achieved with split-sample cross-validation. The external validation is, by definition, independent of the calibration data set because the samples included in the validation data set were not used to calibrate the prediction equations. The $\mathrm{R}$ was greatest when up to 20 factors were included in the prediction equations. These predictions were undertaken including only MIR 
Table 2. Correlations between energy status component variables ${ }^{1}$ and direct energy balance (Direct_EB), energy content (EC), BCS, and effective energy intake (EEI) across the entire lactation and in early lactation ${ }^{2}$

\begin{tabular}{|c|c|c|c|c|c|c|c|c|}
\hline \multirow[b]{2}{*}{ Variable } & \multicolumn{4}{|c|}{ Across lactation $(\mathrm{n}=589)^{3}$} & \multicolumn{4}{|c|}{ Early lactation $(\mathrm{n}=125)^{3}$} \\
\hline & Direct_EB & $\mathrm{EC}$ & $\mathrm{BCS}$ & EEI & Direct_EB & $\mathrm{EC}$ & BCS & EEI \\
\hline Fat $(\%)$ & 0.04 & 0.27 & 0.19 & -0.05 & -0.33 & 0.23 & 0.18 & -0.07 \\
\hline Protein (\%) & 0.14 & 0.34 & 0.22 & -0.01 & -0.18 & 0.09 & 0.00 & -0.01 \\
\hline DMI $(\mathrm{kg})$ & 0.61 & 0.34 & 0.04 & 1.00 & 0.56 & 0.36 & -0.03 & 1.00 \\
\hline BCS & 0.25 & 0.78 & 1.00 & 0.04 & -0.15 & 0.77 & 1.00 & -0.03 \\
\hline
\end{tabular}

spectral data in the prediction model; when milk yield was included as a predictor, the optimum number of explanatory factors was also approximately 20 .

The average R of predicting Direct_EB, EC, BCS, and EEI across all data sets when using unsmoothed MIR spectral data from a.m., MD, or p.m. milk is presented in Table 3. The average number of prediction factors used in the partial least squares models ranged from between 14 and the maximum permitted, 20 . The $\mathrm{R}$ of prediction using external validation was consistently lower than split-sample cross-validation; this was also reflected in greater root mean square error in the external validation data set. On average, the $\mathrm{R}$ of prediction using external validation ranged from 0.67 to 0.72 for Direct_EB, but was lower for EC, ranging from 0.43 to 0.54 . The $\mathrm{R}$ of predicting Direct_EB, $\mathrm{EC}, \mathrm{BCS}$, and EEI was greatest when predictions were made using the p.m. milk samples. The average slope between predicted and actual values of Direct_EB in the validation data sets was not different $(P>0.05)$ from 1, indicating that, on average, a unit difference in actual Direct_EB was also reflected in a difference in predicted Direct_EB of 1 unit. In contrast, the average slope between predicted and true values of EC ranged from 0.77 to 0.83 and was different $(P<0.05)$ from 1 . The mean bias of predicting body energy status in the individual external validation data sets ranged from negative values, where models tended to over-predict values, to positive values where models tended to under-predict values. The maximum bias for any given data set is presented in Table 3 for a.m., MD, and p.m. milk samples. Models consistently under-predicted EC; however, both positive and negative maximum bias values were observed for both Direct_EB and EEI.

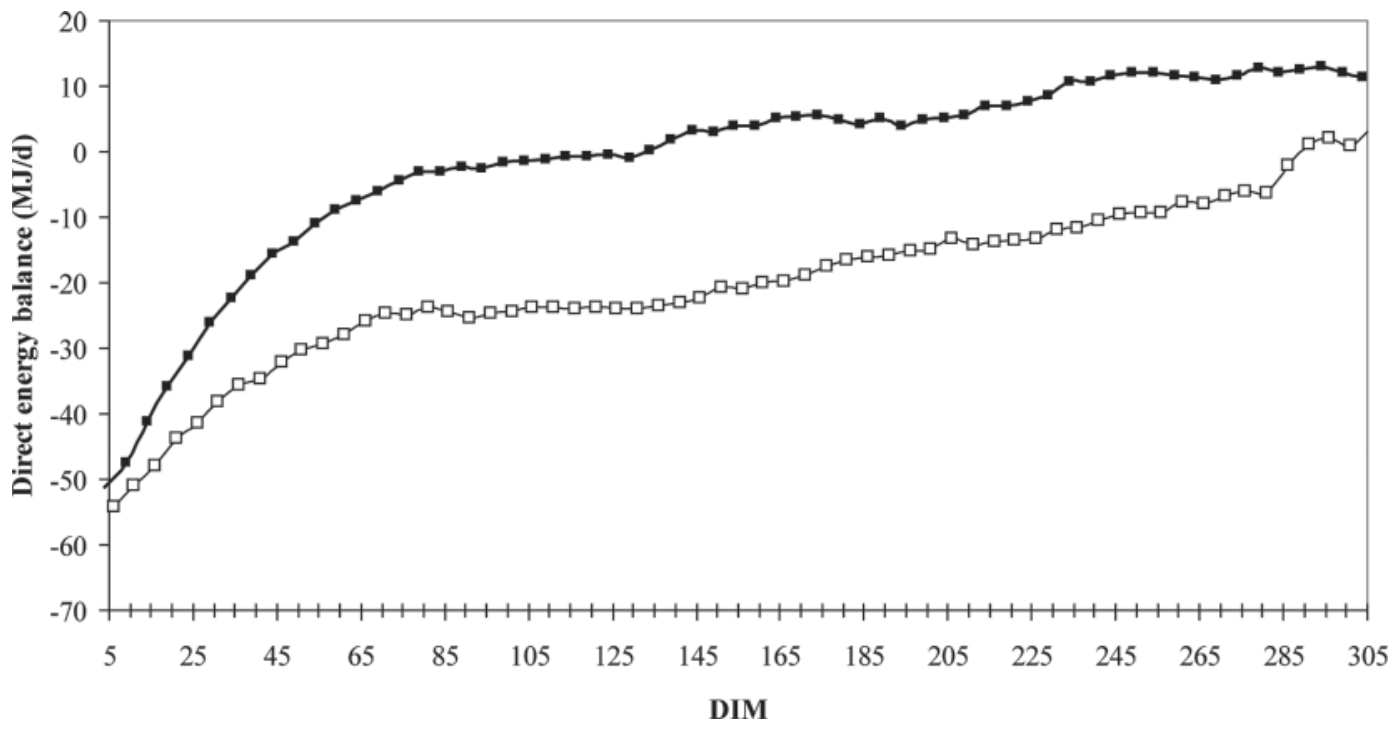

Figure 1. Average direct energy balance lactation profiles for cows in the high-concentrate (- - -) and low-concentrate (- $\square$-) experimental feeding groups. 
(a)

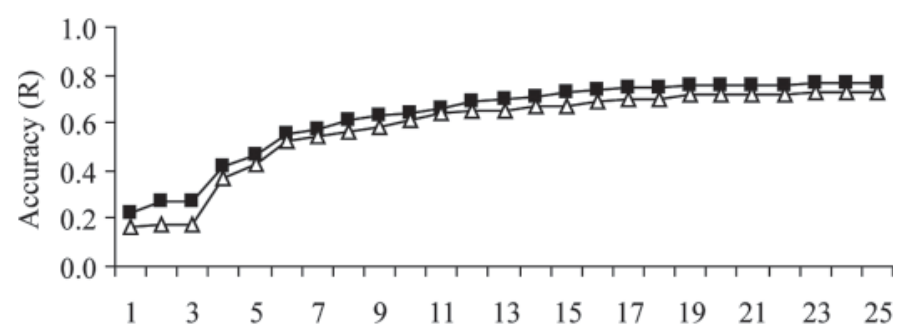

(b)

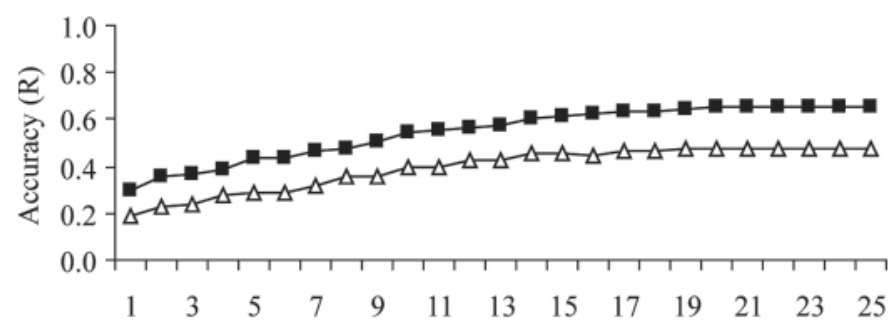

(c)

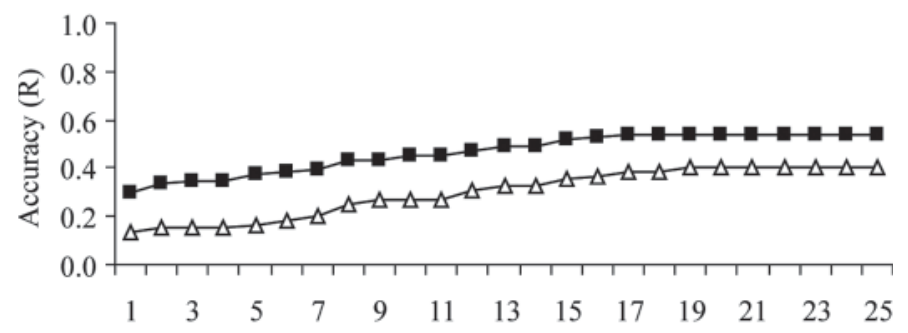

(d)

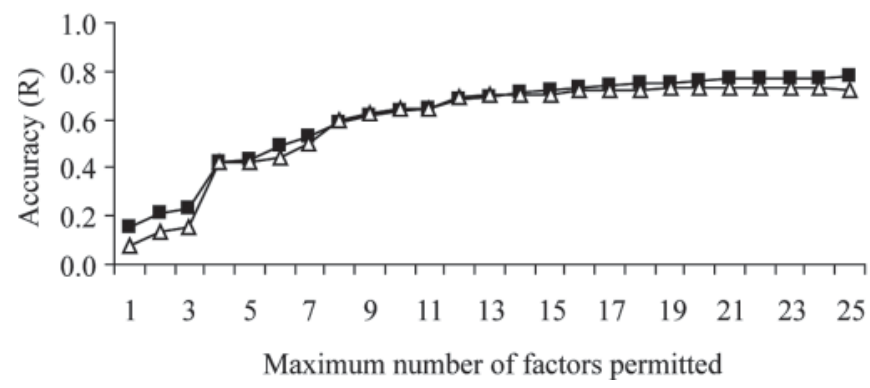

Figure 2. Influence of the maximum number of predictive factors permitted in the calibration equation on the accuracy (R) of the splitsample cross-validation (-口-) and external validation (- - -) when predicting (a) direct energy balance, (b) energy content, (c) BCS, and (d) effective energy intake. The $\mathrm{R}$ of prediction was defined as the square root of the coefficient of determination from the regression model of true on predicted values of body energy status.

Using smoothed MIR wavelengths in the prediction model did not improve the $\mathrm{R}$ of prediction over the $\mathrm{R}$ obtained using the unsmoothed wavelengths. Similarly, the use of the first derivative of the smoothed or un- smoothed MIR wavelengths did not yield more accurate predictions. These results are, therefore, not presented.

Including milk yield in the prediction model increased the R of predicting Direct_EB by between 0.02 and 0.03 units, whereas the $\mathrm{R}$ of predicting EEI increased by between 0.15 and 0.18 units (Table 4). For Direct_EB and EEI, the slope between predicted and true values was closer to 1 or unchanged by including milk yield in the model and the maximum bias for any individual validation data set was also closer to zero. However this was not always true for analyses of EC.

\section{Accuracy of Prediction at Different Stages of Lactation}

Table 5 summarizes the average $\mathrm{R}$ of predicting body energy status during early lactation using the MIR spectral data and the corresponding milk yield for the a.m., MD, and p.m. milk samples. In early lactation, fewer explanatory factors were required in the prediction model to achieve maximum $\mathrm{R}$. The maximum number of prediction factors permitted in prediction models was 12; however, the number of factors used by the models ranged from between 5 and 11 .

Although, on average, prediction $\mathrm{R}$ at specific stages of lactation were lower when compared with predictions made across lactation, likely because of the small size of the data sets, the $\mathrm{R}$ obtained from the individual data sets were inconsistent. In one external validation data set, the $\mathrm{R}$ of predicting Direct_EB in early lactation was as high as 0.78 , yet low accuracies $(\mathrm{R}=0.51)$ in other validation data sets were also observed.

Compared with early lactation, lower prediction $\mathrm{R}$ for Direct_EB were obtained when predictions were undertaken in mid or late lactation (results not shown). In contrast, the best predictions of BCS were achieved in midlactation. The average $\mathrm{R}$ of predicting $\mathrm{BCS}$ in midlactation using MD milk samples was 0.42.

\section{Accuracy of Prediction Across Feed Systems}

A summary of the $\mathrm{R}$ of predicting energy status and EEI using prediction equations calibrated using data from cows on the high-concentrate diet and externally validated on the low-concentrate group is presented in Table 6. External validation yielded poor $\mathrm{R}$ of prediction when compared with previous results where both concentrate groups were included in the calibration data set. Similarly, poor R of prediction were obtained when the prediction equations were developed using data from the low-concentrate diet and applied to the high-concentrate diet group (results not shown). 
Table 3. Number of records, average number of factors (Fac), root mean square error (RMSE), correlation coefficient, maximum bias (SE in parentheses), ${ }^{1}$ and slope (b; SE in parentheses) ${ }^{2}$ obtained from predicting direct energy balance (Direct_EB), energy content, BCS, and effective energy intake (EEI) using unsmoothed mid-infrared spectra, tested using split-sample cross-validation and external validation methods, across all data sets

\begin{tabular}{|c|c|c|c|c|c|c|c|c|}
\hline \multirow[b]{2}{*}{ Trait } & \multirow[b]{2}{*}{$\mathrm{n}$} & \multirow[b]{2}{*}{$\mathrm{Fac}$} & \multicolumn{2}{|c|}{$\begin{array}{c}\text { Split-sample } \\
\text { cross-validation }\end{array}$} & \multicolumn{4}{|c|}{ External validation } \\
\hline & & & RMSE & $\mathrm{r}$ & Bias (SE) & b (SE) & RMSE & $\mathrm{r}$ \\
\hline \multicolumn{9}{|l|}{ a.m. milk samples } \\
\hline Direct_EB (MJ/d) & 1,883 & 20 & 21.06 & 0.72 & $3.18(1.21)$ & $0.93(0.05)$ & 22.18 & 0.68 \\
\hline Energy content (MJ) & 1,883 & 14 & 833.6 & 0.56 & $-330(56)$ & $0.77(0.07)$ & 876.44 & 0.43 \\
\hline $\mathrm{BCS}$ & 1,883 & 15 & 0.26 & 0.51 & $-0.08(0.02)$ & $0.69(0.08)$ & 0.28 & 0.36 \\
\hline Direct_EB (MJ/d) & 1,731 & 19 & 20.96 & 0.71 & $-3.25(1.08)$ & $0.94(0.05)$ & 16.72 & 0.67 \\
\hline Energy content (MJ) & 1,731 & 19 & 784.7 & 0.62 & $-300(44)$ & $0.80(0.06)$ & 833.48 & 0.52 \\
\hline $\mathrm{BCS}$ & 1,731 & 18 & 0.26 & 0.53 & $-0.07(0.01)$ & $0.75(0.08)$ & 0.27 & 0.41 \\
\hline EEI (MJ) & 1,731 & 20 & 29.27 & 0.73 & $-5.19(1.69)$ & $0.92(0.05)$ & 31.23 & 0.68 \\
\hline \multicolumn{9}{|l|}{ p.m. milk samples } \\
\hline Direct_EB (MJ/d) & 1,855 & 20 & 19.33 & 0.75 & $-3.16(0.96)$ & $0.95(0.04)$ & 20.32 & 0.72 \\
\hline Energy content (MJ) & 1,855 & 20 & 778.3 & 0.63 & $-192(39)$ & $0.83(0.06)$ & 822.56 & 0.54 \\
\hline
\end{tabular}

${ }^{1}$ Largest average difference between predicted values and true values in any external validation data set.

${ }^{2}$ Linear regression coefficient of true energy status value on predicted value.

\section{Accuracy of Prediction Across Genetic Lines}

The $\mathrm{R}$ of predicting both Direct_EB and EEI through either cross-validation or external validation was lower when the equations were developed using the high genetic line, compared with when equations were developed using the control line. The $\mathrm{R}$ of predicting Direct_EB through external validation was 0.60 when calibrated on the select line and validated on the control line of cows. However the $\mathrm{R}$ of predicting Direct_EB in the select line was 0.68 if equations were developed using the control line of cows. Differences in $\mathrm{R}$ between the cross-validation and external validation methods were similar to the differences seen between these validation methods when tested using all cows across lactation (Table 3).

Table 4. Average number of factors (Fac), root mean square error (RMSE), correlation coefficient, maximum bias (SE in parentheses), ${ }^{1}$ and slope (b; SE in parentheses) ${ }^{2}$ obtained from predicting direct energy balance (Direct_EB), energy content, BCS, and effective energy intake (EEI) using unsmoothed mid-infrared spectra and milk yield, tested using split-sample cross-validation and external validation methods, across all data sets

\begin{tabular}{|c|c|c|c|c|c|c|c|}
\hline \multirow[b]{2}{*}{ Trait } & \multirow[b]{2}{*}{$\mathrm{Fac}$} & \multicolumn{2}{|c|}{$\begin{array}{l}\text { Split sample } \\
\text { cross-validation }\end{array}$} & \multicolumn{4}{|c|}{ External validation } \\
\hline & & RMSE & $\mathrm{r}$ & Bias (SE) & b (SE) & RMSE & $\mathrm{r}$ \\
\hline Direct_EB (MJ/d) & 20 & 20.63 & 0.73 & $-2.74(1.00)$ & $0.94(0.04)$ & 21.68 & 0.70 \\
\hline Energy content (MJ) & 15 & 810.7 & 0.59 & $-334(59)$ & $0.76(0.06)$ & 862.7 & 0.46 \\
\hline $\mathrm{BCS}$ & 16 & 0.26 & 0.53 & $-0.09(0.02)$ & $0.73(0.07)$ & 0.27 & 0.39 \\
\hline \multicolumn{8}{|l|}{ Midday milk samples } \\
\hline Direct_EB (MJ/d) & 19 & 15.6 & 0.73 & $-2.8(1.04)$ & $0.95(0.05)$ & 21.5 & 0.69 \\
\hline Energy content (MJ) & 16 & 775 & 0.63 & $-291(44)$ & $0.82(0.06)$ & 818.88 & 0.54 \\
\hline $\mathrm{BCS}$ & 18 & 0.25 & 0.55 & $-0.08(0.01)$ & $0.76(0.08)$ & 0.27 & 0.43 \\
\hline EEI (MJ) & 19 & 20.83 & 0.87 & $-2.95(1.2)$ & $0.98(0.03)$ & 21.95 & 0.86 \\
\hline \multicolumn{8}{|l|}{ p.m. milk samples } \\
\hline Direct_EB (MJ/d) & 20 & 18.57 & 0.78 & $-3.14(0.90)$ & $0.95(0.04)$ & 19.61 & 0.75 \\
\hline Energy content (MJ) & 19 & 774.2 & 0.63 & $-182(38)$ & $0.85(0.06)$ & 815.5 & 0.55 \\
\hline
\end{tabular}

${ }^{1}$ Largest average difference between predicted values and true values in any external validation data set.

${ }^{2}$ Linear regression coefficient of true energy status value on predicted value. 
Table 5. Number of records, average number of factors (Fac), root mean square error (RMSE), correlation coefficient, maximum bias (SE in parentheses), ${ }^{1}$ and slope (b; SE in parentheses) ${ }^{2}$ obtained from predicting direct energy balance (Direct_EB), energy content, BCS, and effective energy intake (EEI) in early lactation (DIM <61) using unsmoothed mid-infrared spectra and milk yield, tested using split-sample crossvalidation and external validation methods, across all data sets

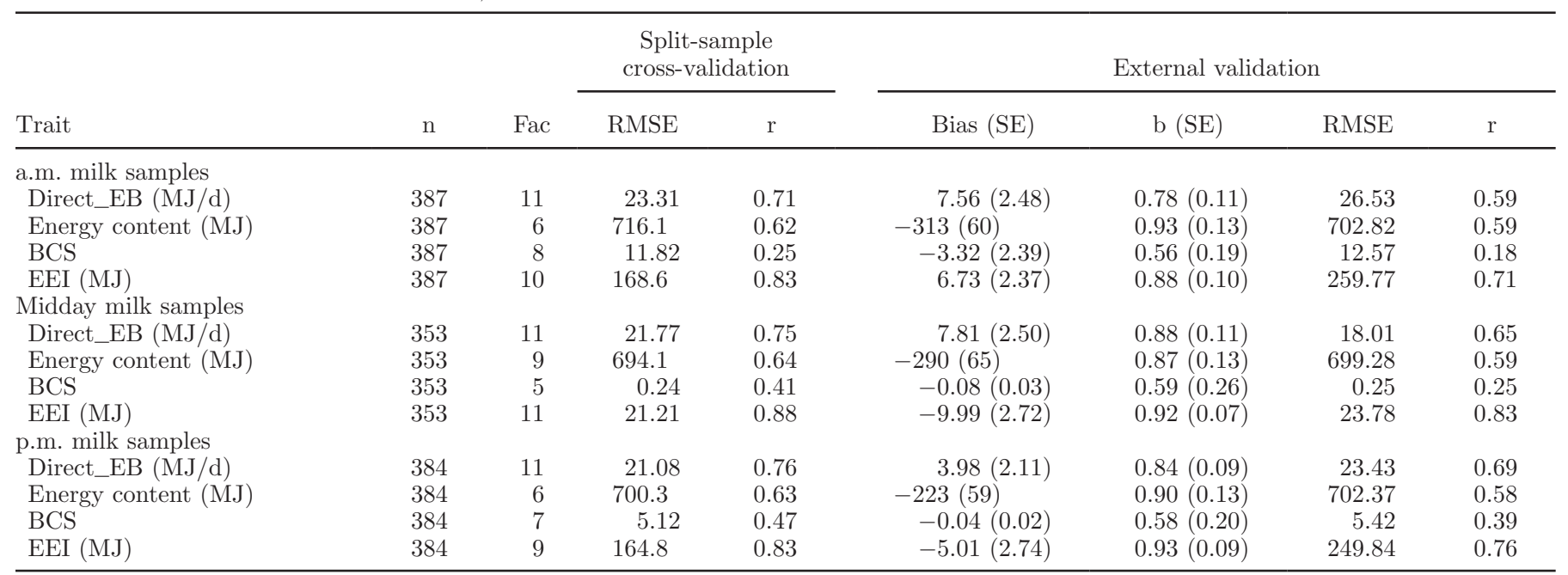

${ }^{1}$ Largest average difference between predicted values and true values in any external validation data set.

${ }^{2}$ Linear regression coefficient of true energy status value on predicted value.

\section{DISCUSSION}

The objective of this study was to predict body energy status of lactating Holstein cows using routinely available milk MIR spectral data. Accurate, routine, and freely available information on body energy status of individual cows would be useful for farmers as a management aid to identify cows with a greater likelihood of succumbing to health and wellbeing problems but would also provide useful information for inclusion in genetic evaluations. However, true energy balance is an expensive trait to accurately measure, and to date, proposed methods of predicting energy balance are suboptimal because high $\mathrm{R}$ of prediction is not consistently achievable across studies, particularly at an individual animal level (Reist et al., 2002; Friggens et al., 2007). Because traits derived from milk components, such as fat-to-protein ratio and milk fatty acid composition,

Table 6. Number of factors (Fac), root mean square error (RMSE), correlation coefficient, mean bias (SE in parentheses), ${ }^{1}$ and slope (b; SE in parentheses) $)^{2}$ obtained from predicting direct energy balance (Direct_EB), energy content, BCS, and effective energy intake (EEI) of cows on a low-concentrate diet using a prediction equation calibrated from cows on a high-concentration diet, tested using split-sample cross-validation and external validation methods

\begin{tabular}{|c|c|c|c|c|c|c|c|}
\hline \multirow[b]{2}{*}{ Trait } & \multirow[b]{2}{*}{$\mathrm{Fac}$} & \multicolumn{2}{|c|}{$\begin{array}{c}\text { Split-sample } \\
\text { cross-validation }\end{array}$} & \multicolumn{4}{|c|}{ External validation } \\
\hline & & RMSE & $\mathrm{r}$ & Bias (SE) & $\mathrm{b}(\mathrm{SE})$ & RMSE & $\mathrm{r}$ \\
\hline Direct_EB $(\mathrm{MJ} / \mathrm{d})$ & 17 & 15.10 & 0.76 & $-23.19(1.10)$ & $0.70(0.06)$ & 33.19 & 0.35 \\
\hline Energy content (MJ) & 13 & 843.32 & 0.53 & $-467(29)$ & $0.67(0.05)$ & 857.70 & 0.40 \\
\hline $\mathrm{BCS}$ & 13 & 0.25 & 0.58 & $-0.27(0.01)$ & $0.49(0.05)$ & 0.26 & 0.31 \\
\hline Direct_EB (MJ/d) & 16 & 14.94 & 0.76 & $-23.16(1.18)$ & $0.56(0.08)$ & 34.11 & 0.22 \\
\hline Energy content (MJ) & 19 & 782.45 & 0.62 & $-376(29)$ & $0.69(0.05)$ & 825.99 & 0.44 \\
\hline BCS & 10 & 0.26 & 0.55 & $-0.30(0.01)$ & $0.59(0.06)$ & 0.26 & 0.34 \\
\hline EEI (MJ) & 18 & 17.04 & 0.84 & $-21.35(1.05)$ & $1.19(0.04)$ & 30.28 & 0.68 \\
\hline \multicolumn{8}{|l|}{ p.m. milk samples } \\
\hline Direct_EB (MJ/d) & 19 & 14.80 & 0.78 & $-16.95(0.94)$ & $1.12(0.06)$ & 28.60 & 0.54 \\
\hline Energy content (MJ) & 20 & 799.83 & 0.60 & $-224(28)$ & $0.71(0.05)$ & 832.02 & 0.44 \\
\hline
\end{tabular}

${ }^{1}$ Average difference between predicted values and true values in the external validation data set.

${ }^{2}$ Linear regression coefficient of true energy status value on predicted value. 
are all predicted from MIR spectral data and have been proposed to be related to energy balance (Reist et al., 2002; Friggens et al., 2007), the hypothesis for this study was that MIR spectral data in its own right would be useful as a predictor of body energy status.

\section{Development of Prediction Equations}

An important consideration in the development of a prediction model is the number of explanatory factors permitted in the model. If too few explanatory variables are included, the resulting model is oversimplified and unable to predict with enough R, especially in an independent data set. In contrast, if too many explanatory factors are included, the model is potentially over-parameterized to its calibration data set and is also unable to achieve high $\mathrm{R}$ of prediction in an external data set. The external validation procedure is based on testing the $\mathrm{R}$ in an independent data set; thus, results from external validation represent a truer reflection of the $\mathrm{R}$ of the prediction equations than the $\mathrm{R}$ reported from split-sample cross-validation. For this reason, the effect of increasing the number of prediction factors permissible in the model was tested on both the split-sample cross-validation and external validation $\mathrm{R}$ (Figure 2). It is clear that, as the number of factors permissible in the model increased, the $\mathrm{R}$ of both validation procedures increased, yet at some point (20 explanatory factors), the $\mathrm{R}$ of the external validation began to decrease. This is likely due to over-parameterization of the model, thereby possibly modeling some inherent error in the calibration database. The error may improve the $\mathrm{R}$ of the equation in the calibration data set, yet could decrease the $\mathrm{R}$ of the equation on independent data (i.e., external validation data set). Therefore, a maximum of 20 factors was chosen for the majority of prediction models in this study. For prediction models developed during early lactation, a maximum of 12 explanatory factors was chosen. These numbers of explanatory factors are in the range of those reported by other studies; Soyeurt et al. (2011) set the maximum number of factors in their prediction model for milk fatty acid equal to 16 .

The lack of improvement in $\mathrm{R}$ from pretreatment of the spectral data, such as smoothing or using the rate of change across the MIR data wavelengths, is contrary to previous work published (Soyeurt et al., 2011) when attempting to predict milk fatty acid composition from spectral data. The first derivative of the smoothed spectral data accentuates large deviations in spectral values from one wavelength to the next. Using the first derivative of MIR spectral data, Soyeurt et al. (2011) reported a slight improvement in prediction of some milk fatty acids. The largest improvement reported was an increase in coefficient of determination value from 0.80 to 0.84 for C18:1 trans. Pre-treatment of spectral data also resulted in poorer predictions for some fatty acids (Soyeurt et al., 2011). However, unlike the study of Soyeurt et al. (2011), the results presented here used MIR data collected from a single spectrometer, and all MIR spectral data were collected in a relatively short time period, under $2 \mathrm{yr}$.

External validations of the prediction of body energy status when the calibration data set did not represent or imitate the validation data set were poor (Table 6). The prediction equations calibrated using data from the high-concentrate experimental group only was unable to predict body energy status in the low-concentrate experimental group and vice versa, despite achieving high $\mathrm{R}$ with split-sample cross-validation. However, as seen in Figure 1, the 2 feeding groups had very different average Direct_EB lactation profiles with little overlap observed. Accurate predictions can only be obtained for cows when actual phenotypic data on animals in similar production systems with similar energy balance profiles have been quantified and included in the calibration of the prediction equations. This limits the applicability of the prediction equations across different production systems, unless phenotypic records representative of those systems are included in the calibration of prediction models.

\section{Prediction of Body Energy Status and Energy Intake}

The greatest $\mathrm{R}$ of predicting energy status in the external validation data set in this study was 0.75 , obtained when predicting Direct_EB using p.m. milk samples across lactation (Table 4). However, by definition, Direct_EB is a noisy phenotype, as it incorporates several phenotypes each with their own individual measurement error; random variation could also have been introduced through the modeling of the individual components during lactation for the subsequent calculation of Direct_EB. The same is true of EC, but to a lesser extent, although BCS is subjectively measured and BW can vary considerably with gut fill; an attempt was made in the present study to account for differences in gut fill in the modeling of EC. Furthermore, diurnal variation in body energy status traits or energy intake may also exist. This was reflected in the different milkings during the day but would not be evident when these traits were expressed on an average daily basis. This could be one contributing factor to the differences in $\mathrm{R}$ observed, depending on which of the milkings during the day was under investigation. Very high $R$ were, therefore, not expected in the prediction of Direct_EB or EC itself. However, it was not possible to ascertain whether the energy status traits to be predicted are a 
closer reflection of the true energy status of the animal than predictions from the MIR spectral data.

Across all prediction models presented in this study, Direct_EB was the energy status measure that was consistently most accurately predicted. This is not unexpected because milk fat, protein, and lactose, all predicted from MIR spectra, are directly used in the estimation of Direct_EB and, therefore, a statistical part-whole relationship exists between the predictors and the predictand. Furthermore, the improvement in predictions with the inclusion of milk yield in the model was not unexpected, for Direct_EB at least, again because of the statistical part-whole relationship. However, a biological relationship also exists because milk energy output is a key component of a cow's actual energy status. Nevertheless, the greatest improvement in $\mathrm{R}$ from including milk yield in the prediction model was observed in the prediction of EEI, although milk yield was not involved in the calculation of EEI. Both milk yield and EEI were strongly correlated, especially in early lactation, where the correlation between the 2 traits was 0.70 (Table 2). If the use of milk MIR spectra to predict body energy status is implemented in milk-recording schemes, milk yield for each sample will also be available and it is, therefore, sensible to use all available data that add information to the prediction.

The motivation for this study was to evaluate the potential of MIR spectral data to improve the prediction of body energy status over and above previously suggested approaches of fat-to-protein ratio (Heuer et al., 2000; Friggens et al., 2007; Buttchereit et al., 2010) and milk acetone concentration (Clark et al. 2005). The biological rationale behind this hypothesized association is that body fat mobilization occurring when a cow is in negative energy balance leads to an increased uptake of the resulting fatty acids and, subsequently, increased fat synthesis in the udder. Concomitantly decreased intake of fermentable carbohydrates decreases the synthesis of protein by the bacteria in the rumen, thereby decreasing the flow of AA to the udder and, thus, decreasing protein synthesis. Grieve et al. (1986) reported correlations of -0.74 to -0.36 between fatto-protein ratio and energy balance in 236 cows during their second or third month of lactation. Similarly, Reist et al. (2002) documented a correlation of -0.50 between fat-to-protein ratio and energy balance in the first $11 \mathrm{wk}$ of lactation in 90 multiparous Holsteins. These associations are considerably stronger than the associations obtained for predicting Direct_EB using fat-to-protein ratio in this study. Correlations between fat-to-protein ratio and Direct_EB obtained in this study were -0.09 and -0.28 across lactation and in early lactation, respectively. However, other studies also exist, which indicate weak associations between fat-to-protein ratio and energy balance like that observed in this study (Clark et al., 2005); Heuer et al. (2000) reported an increase in the proportion of variance in energy balance explained by fat-to-protein ratio of only 5.6 percentage units when week of lactation, parity, and milk yield were already adjusted for in wk 2 to 12 of lactation. Furthermore, few other studies have attempted to predict energy balance throughout lactation from milk composition, instead focusing on energy balance in early lactation. This is likely because of the known association between negative energy balance in early lactation and subsequent reproductive performance (Butler and Smith, 1989). However, Buttchereit et al. (2010) reported a stronger correlation between fat-to-protein ratio and energy balance in early lactation $(<0.60 \mathrm{DIM})$ of -0.43 to -0.28 compared with later lactation $(-0.28$ to -0.13$)$.

Using partial least squares regression and split-sample cross-validation, Friggens et al. (2007) attempted to predict energy balance and energy content, similar to those defined in the present study, with a series of variables derived from milk yield and milk composition, including number of days since calving. They reported that $39 \%$ of the variation in their definition of energy content (which they referred to as EBal) could be explained by a model that contained days postcalving, milk fat content, fat-to-protein ratio, as well as the first derivatives of daily milk yield, fat-to-protein ratio and lactose yield; the same model explained $50 \%$ of the variation in their definition of energy balance (which they referred to as EBinout). Slightly better R of predicting Direct_EB and EC were generally observed in the present study across lactation, in the model that also included milk yield, suggesting that the prediction equations developed in the present study are exploiting information from the MIR spectra over and above their association with the major components of milk such as fat, protein, and lactose.

\section{CONCLUSIONS}

This study offers a method to cheaply and accurately predict body energy status of cows using routine milk recording. Although $\mathrm{R}$ of prediction are greater than previously reported for predictions of energy status in individual cows, the prediction equations were not robust across feeding systems that were not represented in the data set used to generate the equations. Further research will need to be undertaken to evaluate whether the measures of energy status predicted in the present study are heritable and more strongly correlated with subsequent health and fertility than previously evaluated measures of energy status. 


\section{ACKNOWLEDGMENTS}

The RobustMilk project is financially supported by the European Commission under the Seventh Research Framework Programme, Grant Agreement KBBE211708. The authors gratefully acknowledge the work by Ainsley Bagnall and staff at Crichton Research Farm (Dumfries, Scotland) and the assistance of Ross McGinn (Scottish Agricultural College, UK) in collating the phenotypic data used in this study.

\section{REFERENCES}

Banos, G., and M. P. Coffey. 2010. Genetic association between body energy measured throughout lactation and fertility in dairy cattle. Animal 4:189-199.

Beam, S. W., and W. R. Butler. 1999. Effects of energy balance on follicular development and first ovulation in postpartum dairy cows. J. Reprod. Fertil. Suppl. 54:411-424.

Berry, D. P., B. Horan, M. O'Donovan, F. Buckley, E. Kennedy, M. McEvoy, and P. Dillon. 2007. Genetics of grass dry matter intake, energy balance and digestibility in Irish dairy cows. J. Dairy Sci. 90:4835-4845.

Butler, W. R., and R. D. Smith. 1989. Interrelationships between energy balance and postpartum reproductive function in dairy cattle. J. Dairy Sci. 72:767-783.

Buttchereit, N., E. Stamer, W. Junge, and G. Thaller. 2010. Evaluation of five lactation curve models fitted for fat:protein ratio of milk and daily energy balance. J. Dairy Sci. 93:1702-1712.

Clark, C. E. F., W. J. Fulkerson, K. S. Nandra, I. Barchia, and K. L. Macmillan. 2005. The use of indicators to assess the degree of mobilisation of body reserves in dairy cows in early lactation on a pasture-based diet. Livest. Prod. Sci. 94:199-211.

Coffey, M. P., G. Simm, W. G. Hill, and S. Brotherstone. 2003. Genetic evaluations of dairy bulls for daughter energy balance profiles using linear type scores and body condition score analyzed using random regression. J. Dairy Sci. 86:2205-2212.
Collard, B. L., J. C. M. Dekkers, D. Petitclerc, and L. R. Schaeffer. 2000. Relationships between energy balance and health traits of dairy cattle in early lactation. J. Dairy Sci. 83:2683-2690.

Emmans, G. C. 1994. Effective energy: A concept of energy utilization applied across species. Br. J. Nutr. 71:801-821.

Friggens, N. C., C. Ridder, and P. Løvendahl. 2007. On the use of milk composition measures to predict energy balance of dairy cows. J. Dairy Sci. 90:5453-5467.

Gilmour, A. R., B. J. Gogel, B. R. Cullis, and R. Thompson. 2006 ASReml User Guide, Release 2.0. VSN Inter. Ltd., Hemel Hempstead, UK.

Grieve, D. G., S. Korver, Y. S. Rijpkema, and G. Hof. 1986. Relationship between milk composition and some nutritional parameters in early lactation. Livest. Prod. Sci. 14:239-254.

Heuer, C., W. M. Van Straalen, Y. H. Schukken, A. Dirkzwager, and J. P. T. M. Noordhuizen. 2000. Prediction of energy balance in a high yielding hairy herd in early lactation: Model development and precision. Livest. Prod. Sci. 65:91-105.

Lowman, B. G., N. Scott, and S. Somerville. 1976. Condition scoring of cattle. Revised edition. Bulletin of the East Scotland College of Agriculture, No. 6.

Pryce, J. E., B. L. Nielsen, R. F. Veerkamp, and G. Simm. 1999 Genotype and feeding system effects and interactions for health and fertility traits in dairy cattle. Livest. Prod. Sci. 57:193-201.

Reist, M., D. Erdin, D. Von Euw, K. Tschuemperlin, H. Leuenberger, Y. Chilliard, H. M. Hammon, C. Morel, C. Philipona, Y. Zbinden, N. Kuenzi, and J. W. Blum. 2002. Estimation of energy balance at the individual and herd level using blood and milk traits in highyielding dairy cows. J. Dairy Sci. 85:3314-3327.

Soyeurt, H. F., N. Dehareng, S. Gengler, E. McParland, D. P. Wall, M. Berry, Coffey, and P. Dardenne. 2011. Mid-infrared prediction of bovine milk fatty acids across multiple breeds, production systems, and countries. J. Dairy Sci. 94:1657-1667.

Stoop, W. M., H. Bovenhuis, J. M. L. Heck, and J. A. M. van Arendonk. 2009. Effect of lactation stage and energy status on milk fat composition of Holstein-Friesian cows. J. Dairy Sci. 92:1469-1478.

Veerkamp, R. F., J. J. Oldenbroek, H. J. Van Der Gaast, and J. H. J. Van Der Werf. 2000. Genetic correlation between days until start of luteal activity and milk yield, energy balance and live weights. J. Dairy Sci. 83:577-583.

Williams, P. 2007. Near-infrared technology - Getting the best out of light. Edition 5.0. PDK Grain, Nanaimo, BC, Canada. 